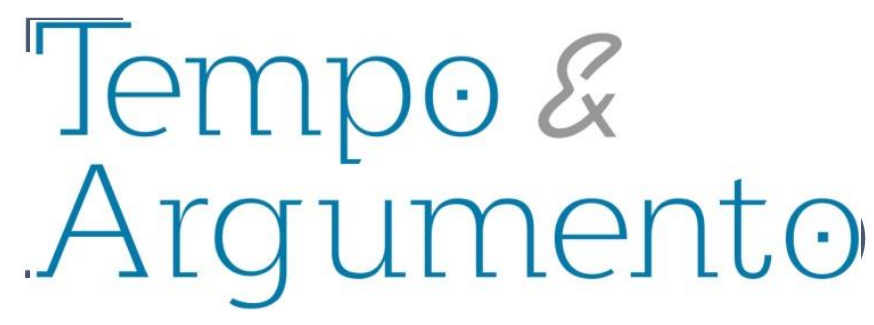

\title{
A História das Mulheres (séc. XX - XXI): entre poder, resistência e subjetivação
}

\begin{abstract}
Resumo
Neste artigo, analisamos a potência produtiva e criativa de práticas de resistência na história das mulheres contra os efeitos das relações de poder instituídas que assujeitam e aviltam a vida. Aproximamo-nos dos estudos pós-estruturalistas e dos estudos feministas e destacamos principalmente as contribuições de Michel Foucault no que se refere à noção de resistência e às reflexões de Gilles Deleuze sobre a obra foucaultiana. Entendemos que as práticas de resistência representam um trabalho sobre si e possibilitam a criação de gestos ativos e transgressores capazes de constituir novos modos de existência, novas subjetividades. A análise mostra que as práticas de resistência na história das mulheres, contra os efeitos de poder do mandato patriarcal, são ações que podemos chamar de menores, de desviantes, mas com força para produzir espaços de liberdade; são forças potencializadoras de outras formas de existência, capazes de compor outras formas de vida; vidas que agem em vez de apenas reagir às práticas instituídas. Nesse sentido, afastamo-nos das concepções que veem nas práticas de resistência apenas oposições ou reações ao poder e buscamos ressaltar que as práticas de resistência instauram fissuras, abalos nos modos de vida estabelecidos e potencializam outras formas de existência. O desafio consiste em encontrar mecanismo para ampliar cada vez mais as ressonâncias desses abalos, dessas fissuras.
\end{abstract}

Palavras-chave: Poder. Subjetividade. Mulheres. História.

\author{
Losandro Antonio Tedeschi \\ Doutor em História pela Universidade do \\ Vale do Rio dos Sinos (UNISINOS). \\ Professor da Universidade Federal da \\ Grande Dourados (UFGD). Coordenador \\ Cátedra UNESCO "Gênero, Diversidade \\ Cultural e Fronteira". \\ Dourados - MS - BRASIL \\ losandrotedeschi@ufgd.edu.br \\ orcid.org/0000-0002-7454-8349
}

\section{Sirley Lizott Tedeschi}

Doutora em Educação pela Universidade Católica Dom Bosco (UCDB). Professora da Universidade Estadual de Mato Grosso do Sul (UEMS). Pesquisadora da Cátedra UNESCO "Gênero, Diversidade

Cultural e Fronteira".

Dourados - MS - BRASIL tedeschi@uems.br orcid.org/0000-0002-4557-8282

\section{Para citar este artigo:}

TEDESCHI, Losandro Antonio; TEDESCHI, Sirley Lizott. A História das Mulheres (séc. XX - XXI): entre poder, resistência e subjetivação. Tempo e Argumento, Florianópolis, v. 11, n. 26, p. 508 - 529, jan./abr. 2019. 


\title{
Women history (XX-XXIC): among power, resistance and subjectification
}

\begin{abstract}
In this article, we analyze the productive and creative power of resistance practices in the history of women against the effects of established power relations that subject and degrade life. We approach post-structuralist studies and feminist studies, and, mainly, we highlight Michel Foucault's contributions to the notion of resistance and to Gilles Deleuze's reflections on Foucault's work. We understand that resistance practices represent a work about oneself and enable the creation of active and transgressive gestures capable of forming new modes of existence, new subjectivities. The analysis shows that the practices of resistance in the history of women, against the power effects of patriarchal mandate, are actions that we can call minor, deviant, but strong enough to produce spaces of freedom; they are potential forces of other forms of existence, capable of composing other forms of life; lives that act instead of just react against established practices. Thus, we move away from conceptions that consider the practices of resistance mere oppositions or reactions to power and we try to emphasize that practices of resistance establish fissures, shakes in established ways of life and potentiate other forms of existence. The challenge consists in finding a mechanism to expand more and more the resonances of these shakes, of these fissures.
\end{abstract}

Keywords: Power. Subjectivity. Women. History. 


\section{1- Introdução}

No texto Sobre a genealogia da ética, que compõe a obra Ditos e Escritos IX, Foucault (2014) diz que seu trabalho se desenvolve a partir de três importantes domínios genealógicos. O eixo da verdade, desenvolvido em $O$ nascimento da clínica e em $A$ arqueologia do saber, que apresenta uma ontologia histórica de nós mesmos em nossas relações com a verdade; o eixo do poder, apresentado em Vigiar e Punir, em que desenvolve uma ontologia histórica de nós mesmos em nossas relações com um campo de poder; e o eixo da moral, apresentado em A História da Sexualidade, em que apresenta uma ontologia histórica de nossas relações com a moral e que possibilita nos constituirmos como agentes éticos.

Deleuze (2013b) diz que Foucault, para desenvolver sua análise, promove três deslocamentos teóricos. O primeiro deslocamento foi necessário para analisar o progresso do conhecimento - perguntar pelas formas de práticas discursivas que articulam o saber; o segundo deslocamento possibilitou analisar as manifestações do poder - perguntar pelas relações múltiplas, pelas estratégias abertas e pelas técnicas racionais que articulam o exercício dos poderes; o terceiro deslocamento levou à análise do sujeito - pesquisar as formas e as modalidades da relação consigo através das quais o indivíduo se constitui e se reconhece como sujeito. Assim, Foucault se propõe a abordar três problemas importantes que perpassam toda sua obra e correspondem a três domínios extremamente articulados em seu pensamento, de modo que não é possível compreendê-los separadamente: o saber, o poder e o sujeito.

Se na década de 1970 Foucault tinha analisado as formações do saber e os dispositivos de poder, "tinha atingido esses mistos de poder-saber nos quais vivemos e falamos" (DELEUZE, 2013b, p. 139), na década de 1980 - nos cursos A hermenêutica do sujeito, História da sexualidade: os usos dos prazeres e $O$ cuidado de si - o foco deixa de estar nos jogos de poder-saber e se coloca nos jogos do sujeito consigo mesmo, ou seja, nos processos de subjetivação.

Em uma entrevista concedida a Claire Parnet, Deleuze (2015) diz que se Foucault, em A vontade de saber, ainda estava em busca dos focos de poder que constituem os enunciados da sexualidade, normalizando ou os contestando, em $\mathrm{O}$ uso dos Prazeres 
busca estabelecer novas relações com o saber e o poder. Mesmo que no texto $A$ vida dos homens infames Foucault diga que "o ponto mais intenso das vidas, aquele em que se concentra sua energia, é bem ali onde elas se chocam com o poder, se debatem com ele, tentam utilizar suas forças ou escapar de suas armadilhas", (FOUCAULT, 2015, p. 204) ele parece não se satisfazer com isso, ele precisa, conforme Deleuze (2013b), de "um pouco de possível”.

Por isso, em O uso dos Prazeres, o foco está na relação consigo. O autor reorienta toda sua pesquisa - se até então havia analisado formações históricas de curta duração (séculos XVII-XIX), agora se dedica a formações de longa duração (desde os gregos) - em torno dos modos de subjetivação. Deleuze diz que isso não representa, de forma alguma, um retorno de Foucault ao sujeito; "era uma nova criação, uma linha de ruptura, uma nova exploração onde mudavam as relações precedentes com o saber e o poder" (DELEUZE, 2013b, p. 135). Ou seja, diante do risco de um fechamento nas relações de poder - expresso por Foucault quando diz a si mesmo: “isso é bem próprio de você, sempre a mesma incapacidade de ultrapassar a linha, de passar para o outo lado, de escutar e fazer ouvir a linguagem que vem de outro lugar ou de baixo, sempre a mesma escolha, do lado do poder" (FOUCAULT, 2015, p. 204) -, o autor faz irromper núcleos de resistência.

O intento de Foucault consiste em mostrar as possibilidades que temos de nos constituir como "si", para além do saber e do poder. Daí, podemos entender o autor quando, em Vigiar e Punir, diz que "temos que ouvir o ronco surdo da batalha" mesmo que sejamos efeito e instrumento de complexas relações de poder.

É nesse sentido que propomo-nos a refletir sobre a potência produtiva e criativa de práticas de resistência na história das mulheres contra os efeitos das relações de poder instituídas que assujeitam e aviltam a vida. Tomamos como referência para a

\footnotetext{
${ }^{1}$ Gallo (2015) destaca a importância conceitual da palavra "si" para Foucault. Diz que para Foucault "a relação de si consigo não é uma relação de identidade. A identidade não é uma questão para Foucault, a constituição de si mesmo não é a construção de uma identidade, mas uma maneira de estar no mundo, com os outros e consigo mesmo" (GALLO, 2015, p. 430). Na mesma perspectiva, Gros (2006) diz que o cuidado de si para Foucault não consiste em "uma exigência de solidão, mas uma verdadeira prática social, um intensificador das relações sociais" (GROS, 2006, p. 250). Cuidar de si, nesse caso, diz Gros (2011), é um convite ao bom governo dos homens - cuidar de si a fim de poder cuidar dos outros.
} 
análise os estudos pós-estruturalistas e os estudos feministas e destacamos, principalmente, as contribuições de Michel Foucault no que se refere à noção de resistência e, às reflexões de Gilles Deleuze, sobre a obra foucaultiana.

Analisamos, em um primeiro momento, as práticas de resistência na obra de Foucault a fim de mostrar que as resistências representam um trabalho sobre si e possibilitam a criação de gestos ativos e transgressores capazes de constituir novos modos de existência, novas subjetividades. Trata-se, conforme Pellejero, de compreender as práticas de resistência como potencializadoras da constituição de modos outros de existência, "da invenção de possibilidades de vida, da criação de territórios existenciais, seguindo regras facultativas, capazes de resistir ao poder como de furtar-se ao saber, mesmo se o saber intenta penetrá-las e o poder de reapropriar-se delas" (PELLEJERO, 2008, p. 01).

Em um segundo momento, analisamos como as práticas de resistência na história das mulheres, contra os efeitos de poder do patriarcado, são potencializadoras de outros modos de existência; são forças capazes de compor outras formas de vida; vidas que agem em vez de apenas reagir às práticas instituídas. Nesse sentido, afastamo-nos das concepções que veem nas práticas de resistência apenas oposições ou reações ao poder - embora opor-se a uma dada situação também seja uma estratégia importante de luta, visto que muitas vezes, nas margens de uma oposição, configuram-se forças que modificam o curso dos processos estabelecidos - e buscamos ressaltar a produtividade e a positividade das práticas de resistência na história das mulheres nos modos de invenção de si.

A partir das discussões desenvolvidas por Foucault e das reflexões de Deleuze sobre a obra do autor, mostramos que as práticas de resistência na história das mulheres instauram fissuras, abalos nos modos de existência instituídos - modos de existência historicamente marcados pelo patriarcado - e potencializam outras formas de vida. $O$ desafio consiste em encontrar mecanismos para ampliar cada vez mais as ressonâncias desses abalos, dessas fissuras. Então, as estratégias informais, silenciosas e desviantes das mulheres construíram/constroem uma história feita pelas fissuras e promovem processos de subjetivação - de constituição de si mesmo. 


\section{2- Sobre poder, resistência e subjetivação em Foucault}

Foucault (2015), em nenhum momento, trata o poder como uma entidade coerente, unitária e estável, mas de relações de poder. As relações de poder, diz Revel “supõem condições históricas de emergência complexas e que implicam efeitos múltiplos, compreendidos fora do que a análise filosófica identifica tradicionalmente como o campo do poder" (REVEL, 2005, p. 67). Trata-se do poder como relações de forças, diz Deleuze, e a força nunca está no singular, "ela tem como característica essencial estar em relação com outras forças, de forma que toda força já é relação, isto é poder" (DELEUZE, 2013a, p. 78).

Ao entender o poder como relações de forças, Foucault (2015) se afasta das concepções tradicionais de poder - a "hipótese repressiva do poder" ou sua representação jurídico-discursiva -, em que o poder é uma instância unificada na figura do Estado e age de forma vertical, reprimindo por meio da lei. O autor diz que devemos evitar "localizar o poder no aparelho de Estado, e em fazer do aparelho de Estado o instrumento privilegiado, capital, maior, quase único do poder de uma classe sobre outra classe" (FOUCAULT, 2015, p. 180). Afinal, na perspectiva foucaultiana, o poder funciona sempre em cadeia, tanto em nível molar quanto molecular. Ao privilegiarmos uma concepção molar de poder - macropolítica - dificulta-se a possibilidade de apreender as porosidades dos múltiplos processos sociais - micropolítica. É na coexistência desses processos - macro e micro - que o poder funciona e que as lutas têm sua insurgência.

Partindo de uma microfísica do poder, Foucault analisa as práticas que afetam a produção das subjetividades e as práticas autônomas - "tecnologias do eu" - em que os sujeitos constituem si mesmos de forma diferencial. Nessa perspectiva, as relações de poder não estão na base das relações legais, mas no plano das disciplinas e de seus efeitos de normalização e moralização. Isso implica considerar não a "impotência ou inoperância do poder soberano, mas sim a maior eficácia de um conjunto de poderes que em vez de negar e reprimir, atuavam discretamente na produção de realidades [...] por meio de processos disciplinares e normalizadores" (DUARTE, 2008, p. 47).

Quando Foucault caracteriza as relações de poder como relações de forças, como formas complexas de ação de uns sobre a de outros, está incluindo em sua análise a 
liberdade como um elemento importante. Para o autor, o poder não se exerce senão sobre sujeitos livres, "entendendo-se por isso sujeitos individuais ou coletivos que têm diante de si um campo de possibilidades em que diversas condutas, diversas reações e diversos modos de comportamento podem acontecer" (FOUCAULT, 2013, p. 289). Revel (2005) diz que na análise foucaultiana do poder, não há contradição entre poder e liberdade. Para a autora, ao tornar indissociáveis esses conceitos, Foucault pode reconhecer no poder um papel não somente repressivo, mas produtivo; pode "enraizar os fenômenos de resistência no próprio interior do poder que eles buscam contestar, e não num improvável 'exterior’” (REVEL, 2005, p. 68).

Se "não há relações de poder onde as determinações estão saturadas" (FOUCAULT, 2013, p. 289), então as resistências, para Foucault, são inseparáveis das relações de poder. A questão do poder é indissociável a das resistências ao poder. Essas resistências são postas em ação internamente no próprio movimento dessas relações. As resistências apresentam-se como fragmentadas e focais e se distribuem com maior ou menor densidade no jogo relacional com o poder. Por isso, Foucault (1988) diz que onde há poder, há resistências; que os núcleos de resistências são compatriotas das relações de poder - o que não significa dizer que estejam fadadas ao fracasso ou que sejam simplesmente subprodutos dessas relações.

Embora Foucault (2015) tenha dito que o poder está sempre "ali", que nunca estamos "fora" do poder, que não há margens para que isso aconteça, não significa dizer que se deva admitir uma forma absoluta de domínio. Para o autor, dizer que nunca se está fora do poder não significa que se está completamente capturado por suas armadilhas. No texto Poderes e Estratégias - em entrevista com Jacques Rancière -, Foucault (2015a) se refere às relações de poder e às práticas de resistência da seguinte forma:

Que não há relações de poder sem resistências; que estas são tão mais reais e eficazes quanto mais se formem ali mesmo onde se exercem as relações de poder; a resistência ao poder não tem que vir de fora para ser real, mas ela não é pega na armadilha porque ela é a compatriota do poder. Ela existe tanto mais quanto ela esteja ali onde está o poder; ela é, portanto, como ele, múltipla e integrável a estratégias globais. (FOUCAULT, 2015a, p. 244) 
Dessa perspectiva, as práticas de resistência possuem as mesmas características que as relações de poder: são móveis, produtivas, inventivas. Não representam uma libertação em relação ao poder a partir de um lugar de exterioridade deste; ao contrário, as práticas de resistência ocorrem ali mesmo onde há relações de poder - relações de poder e práticas de resistência são como as duas faces da mesma moeda. Nesse sentido, entendemos que não só as resistências podem fundar novas relações de poder, como novas relações de poder também podem dar origem a novas formas de resistência.

Essas resistências fragmentadas e focais são expressas na obra $A$ vida dos homens infames, quando Foucault (2015) se propõe a analisar um conjunto de documentos inclusive ordens de prisão - para traçar os enviesamentos entre o discurso histórico e o movimento de singularidades. Nessa obra, o autor diz que não podemos nunca ser totalmente armadilhados pelo poder e que é sempre possível mudar suas configurações de força em contextos específicos. Ao falar sobre os dispositivos discursivos e institucionais presentes naqueles documentos, mostra como estes passam a qualificar a vida daqueles considerados infames. Vilela diz que esses textos se relacionavam com a realidade não apenas por "narrarem fatos que remetiam para existências reais e às quais se poderia atribuir uma data e um lugar, mas também porque as palavras rápidas que os compunham, mesmo que falsas ou injustas, tinham ressonância na vida concreta desses indivíduos" (VILELA, 2006, p. 110).

Foucault (2015) diz que essas vidas infames - a mulher espancada, o monge escandaloso, o bêbado inveterado e furioso, o vendedor brigão e tantas outras vidas -, que teriam podido e talvez devido permanecer na invisibilidade, se tornaram visíveis quando se encontraram com o poder. Para o autor, sem esse encontro com o poder, nenhuma palavra estaria nesses documentos para lembrar o trajeto dessas vidas efêmeras e fugidias. Então, o poder que "espreitava essas vidas, que as perseguiu, que prestou atenção, ainda que por um instante, em suas queixas e em seu pequeno tumulto, e que as marcou com suas garras, foi ele que suscitou as poucas palavras que disso nos restam" (FOUCAULT, 2015, p. 203). Mesmo que não seja possível conhecer essas vidas nelas próprias, como podiam ser em “estado livre”, Foucault (2015) diz que podemos ao 
menos fazê-las falar por meio das poucas palavras que constam nesses documentos, ainda que parciais, táticas e mentirosas dos jogos de poder e das relações com ele.

Para Foucault (2015), mesmo diante de relações de poder que nos asfixiam - como era a vida dos "homens infames" -, a "revanche" ao poder é sempre possível, pois as relações de poder nos fazem ver e falar. Ou seja, "o ponto mais intenso das vidas, aquele em que se concentra sua energia, é bem ali onde elas se chocam com o poder, se debatem com ele, tentam utilizar suas forças ou escapar de suas armadilhas" (FOUCAULT, 2015, p. 204).

Nada indicava, diz Foucault (2015), que essas vidas infames surgissem das sombras. Foi preciso que, dentre tantos documentos dispersos e perdidos, esses fossem encontrados e lidos. Foucault (2015) vê nisso uma forma de resistência, uma chance que permite que essas pessoas desprovidas de qualquer glória surjam no meio de tantos mortos, se façam ouvir, continuem manifestando sua raiva, sua inquietação, sua vida e sua desgraça. Diz que as falas breves dessas vidas infames "que vão e vêm entre o poder e as existências, [...] são para estas o único monumento que jamais Ihe foi concedido: é o que Ihes dá, para atravessar o tempo, o pouco de ruído, o breve clarão que as traz até nós" (FOUCAULT, 2015, p. 204).

Isso nos leva a pensar que, ao mesmo tempo em que há uma história de normalizações/normatizações das subjetividades atuando nas diversas instituições sociais, há também, nesses mesmos espaços, uma história das resistências, dos "cuidados de si", das "artes da existência" ou das "tecnologias do eu" sendo produzida e que, em certa medida, ainda permanece desconhecida.

É o caso da história das mulheres, da vida de mulheres que, ao se defrontarem com o poder patriarcal, produziram outros modos de existência, inventaram outras possibilidades de vida. Por isso, ao mesmo tempo em que Foucault (2015) nos leva a pensar que o destino do indivíduo moderno é se chocar com o poder, que é o encontro com o poder que nos faz ver e falar, o autor também se mostra insatisfeito. Deleuze (2013) diz que Foucault não pôde ficar preso no que descobriu, ele tinha a necessidade de transpor a linha do saber-poder, passar para o outro lado, ir mais além. Embora em A 
vontade de saber, o autor já apresentasse pontos de resistência - que, para Deleuze (2013), o estatuto, a origem, a gênese, ainda permaneciam vagos - é a necessidade de pensar a origem desses pontos de resistência que faz emergir o terceiro eixo no pensamento foucaultiano: o sujeito ético.

Nesse movimento de pensamento, o que predomina não são as relações entre formas (domínio do saber), nem as relações de força com outra força (domínios do poder) e sim a relação da força com o "si” mesmo. É isso a subjetivação em Foucault, diz Deleuze "dar uma curvatura à linha, fazer com que ela retorne sobre si mesma, ou que a força afete a si mesma" (DELEUZE, 2013b, p. 145). A constituição do sujeito ético faz emergir algo que escapa dos poderes e dos saberes, embora deles derive. Através disso, seria possível obter os meios de viver; o que de outra forma não seria possível.

No entanto, esse movimento de pensamento feito por Foucault, na tentativa de determinar um espaço possível de resistência e de constituição de si, não representa um retorno ao sujeito como forma de identidade. A esse respeito, Deleuze diz que;

É idiota dizer que Foucault descobre ou reintroduz um sujeito oculto depois de o ter negado. Não há sujeito, mas uma produção de subjetividade: a subjetividade deve ser produzida quando chega $\mathrm{o}$ momento, justamente porque não há sujeito. E o momento chega quando transpomos as etapas do saber e do poder. (DELEUZE, 2013b, p. 145)

Deleuze diz que a subjetivação para Foucault é uma "operação artista" que se distingue do saber e do poder, que não se localiza no saber e no poder; se "distingue de toda a moral, de todo o código moral: ela é ética e estética, por oposição à moral que participa do saber e do poder" (DELEUZE, 2013b, p. 146). Em uma "estética da existência", - ou seja, quando o indivíduo dá a si mesmo e a sua vida uma forma, quando a ação que o indivíduo realiza sobre si mesmo o constitui como sujeito - trata-se não mais de um ajustamento a norma à qual o sujeito se submete, mas sim da criação de uma forma de vida.

Negando a existência de uma essência humana dada, e partindo do entendimento nietzschiano de que os seres humanos se constituem a si mesmos, Foucault, com a estética da existência, destaca a dimensão estética - forma, estilo - que cada um atribui a 
si mesmo e remete-nos à ideia de sujeito em constante mudança; um sujeito perene, que se transforma - e o sentido dessa transformação nunca é definido a priori. Vilela diz que a forma de existência estética, gerada num intenso desejo de liberdade, "passa a delinearse através das práticas e das técnicas de condução da vida - as tecnologias do eu - que dão origem a comportamentos através dos quais se define um estilo de existência" (VILELA, 2006, p. 123). Neste caso, para Gros (2010), o sujeito se autoconstitui ajudandose com técnicas de si, no lugar de ser constituído por técnicas de saber e de poder.

Podemos entender as formas de resistência às diversas relações de poder na história das mulheres como uma dessas práticas e técnicas - "tecnologias do eu" capazes de fazer emergir comportamentos através dos quais vão se constituindo aquilo que Foucault denomina de "vidas outras". Para o autor, "vidas outras"2 refere-se a um modo de existência que tematiza/problematiza a moral de seu tempo, cria embate político, postura ética; vidas que se constituem fora dos critérios da moralidade epistêmica normativa. Afinal, para Foucault, as práticas de resistência têm a potência de atravessar e interrogar os modos de vida instituídos e de produzir outros sentidos.

Deleuze (2013b) diz que as resistências são linhas desobedientes que não cessam de variar e que se movimentam desfazendo os acordos já estabelecidos. Como linhas desobedientes, linhas de fuga ${ }^{3}$, desterritorializações, são elas que vêm em primeiro lugar - embora não se trate de um primado cronológico. Para Deleuze (2013b), são precisamente as linhas de fuga, as desterritorializações que os dispositivos de poder vão tentar corrigir, apreender, cingir, em um movimento de reterritorialização. Por isso, ele diz que o que se coloca como problema é saber "quais são os fluxos de uma sociedade, quais são os fluxos capazes de subvertê-la, e qual é o lugar do desejo em tudo isso?" (DELEUZE, 2006, p. 292).

\footnotetext{
${ }^{2} \mathrm{Na}$ obra A coragem da Verdade, Michel Foucault (2011), ao referir-se ao cinismo antigo, traz o conceito de "vida outra". Para os cínicos, diz Gros (2011), referindo-se a Foucault, "a verdadeira vida não é mais representada como essa existência consumada, que levaria à perfeição qualidades ou virtudes que os destinos ordinários só ressaltam com fraco brilho. Ela se torna, com os cínicos, uma vida escandalosa, inquietante, uma vida 'outra', imediatamente rejeitada, marginalizada" (GROS, 2011, p. 313).

${ }^{3}$ Gilles Deleuze (1998) diz que "a linha de fuga é uma desterritorialização. [...] fugir não é renunciar às ações, nada mais ativo que uma fuga. É o contrário do imaginário. É também fazer fugir, não necessariamente os outros, mas fazer alguma coisa fugir, fazer um sistema vazar como se fura um cano. (...). Fugir é traçar uma linha, linhas, toda uma cartografia. Só se descobre mundos através de uma longa fuga quebrada" (DELEUZE, 1998, p. 49).
} 


\section{3- Sobre práticas de resistência na história das mulheres: a invenção de outros modos de vida}

Deleuze diz que os processos de subjetivação, de constituição de si, em Foucault, “designam a operação pela qual indivíduos ou comunidades se constituem como sujeitos, à margem dos saberes constituídos e dos poderes estabelecidos, podendo dar lugar a novos saberes e poderes" (DELEUZE, 2013b, p. 193). Então, ao subverter os discursos marcados pelo poder patriarcal, as mulheres reivindicam modos específicos de ser sujeito, transpõem, driblam, constroem linhas de fuga, produzem saberes/poderes particulares, locais, regionais, diferenciados, não unânimes, politicamente divergentes e convocam a criação de uma "história outra". Trata-se, agora, de uma história que não aprisiona seus corpos, seus pensamentos, suas sensibilidades.

Por isso a história das mulheres pode ser entendida como "história outra", que possibilita "vidas outras"; uma história que cria e potencializa espaços heterotópicos; que inaugura uma nova relação com as singularidades; que produz uma crítica historiográfica dos "regimes de saber"; que questiona a forma como os saberes históricos são monopolizados e impedidos de circular livremente; que suspeita/suspende as respostas "científicas" e administrativo-burocráticas para a pergunta "quem somos nós?". Dizemos isso porque a história das mulheres se constrói a partir de narrativas históricas que não se enquadram na episteme discursiva patriarcal. Essas narrativas têm produzido valores e representações capazes de dar a perceber diferentes formas de vida, diferentes interpretações, outros códigos de conduta e referências simbólicas. Rago (2014) diz que Foucault, ao entender o discurso como prática discursiva e não discursiva, como materialidade que constitui os objetos e sujeitos de que fala, desafiou a escrita da história a buscar os múltiplos sentidos que podem ser encontrados em cada gesto, atitude, ação, sentimento ou emoção feminina, assim como nas múltiplas formas de resistência.

\footnotetext{
${ }^{4}$ De acordo com Foucault (1984) o espaço heterotópico é o "[...] espaço do fora, no qual somos atraídos para fora de nós mesmos, no qual decorre precisamente a erosão de nossa vida, de nosso tempo, de nossa história, esse espaço que nos corrói e nos sulca é também em si mesmo um espaço heterogêneo [...] aquele no qual se localizam os indivíduos cujo comportamento desvia em relação à média ou à norma exigida" (FOUCAULT, 1994, p. 416).
} 
Pelas margens da história, as mulheres desenvolveram/desenvolvem movimentos de resistência a uma historiografia que excluiu/exclui o privado, o cotidiano, as miudezas da vida, tratando-as como não história. Essas resistências têm desestabilizado os discursos que historicamente silenciaram e invisibilizaram diversos grupos sociais e culturais. Nesse sentido, podemos dizer que essa "história outra" forjada pelas mulheres se dá nas linhas de fuga, nos desvios capazes de subverter o poder patriarcal que controla, normaliza e coage. É no desvio da norma que o poder das mulheres se torna um poder imanente, desterritorializado. Para desterritorializar incessantemente o poder, é preciso reparar, como afirma Thébaud, os "silêncios patriarcais do passado" (THÉBAUD, 2013, p. 71).

De acordo com Perrot (2005), essas relações de poder - imanentes, desterritorializadas - se manifestam na história das mulheres através dos silêncios e dos gestos; nas ruas, no fazer cotidiano e na escrita do privado. Esses espaços comuns do cotidiano das mulheres são dotados de elementos que mostram a existência de outras dimensões de poder nas relações sociais - um poder imanente, cotidiano, "microbiano", que se constitui, segundo Certeau (1996), através de:

[...] práticas microbianas, singulares e plurais, [...] procedimentos que, muito longe de ser controlados ou eliminados pela administração panóptica, se reforçam em uma proliferação legitimada, desenvolvidos e insinuados nas redes de vigilância, combinados segundo táticas ilegíveis, mas estáveis a tal ponto que constituem regulações cotidianas e criatividades sub-reptícias que se ocultam somente e graças aos dispositivos e aos discursos, hoje atravancados, da organização observadora. Esse caminho poderia inscrever-se como uma sequência, mas também como a recíproca da análise que Michel Foucault fez das estruturas de poder. [...] Mas a esses aparelhos produtores de um espaço disciplinar, que práticas do espaço correspondem, do lado onde se joga (com) a disciplina? Na conjuntura presente de uma contradição entre o modo coletivo da gestão e o modo individual de uma reapropriação, nem por isso essa pergunta deixa de ser essencial, caso se admita que as práticas do espaço tecem, com efeito, as condições determinantes da vida social. (CERTEAU, 1996, p. 175)

Isso mostra que, na história, ao mesmo tempo em que atuam processos de normalização, também são colocados em ação os movimentos dos “cuidados de si" e das "artes da existência" que as mulheres produzem e que, em certa medida, ainda 
permanecem invisibilizados. Por isso, precisamos estar atentos, conforme disse Foucault (1983), para “ouvir o ronco surdo da batalha” (FOUCAULT, 1993, p. 269), precisamos prestar atenção nas relações de poder singulares e plurais para potencializar cada vez mais os efeitos das práticas de resistência das mulheres nos modos de invenção de si. Afinal, não temos dúvidas de que as mulheres, ao se encontrarem com o poder, inventaram novas possibilidades de vida.

Nesse sentido, os espaços dados como "femininos" na história - lugares onde as coisas são organizadas, nomeadas e normalizadas a partir de critérios instituídos - são também o espaço em que "vidas outras" se constituem; vidas que fazem emergir novas relações entre o sujeito e a verdade de seu tempo; novas relações que se criam e se recriam de maneira indefinida, inusitada, destemida.

Então, a história das mulheres, mesmo marcada pelo patriarcalismo, também se constitui de ações que podemos chamar, segundo Deleuze e Guattari (2014), de menores $^{5}$, de desviantes, que ousam se conectar ao devir, ao acontecimento e à irrupção do novo. Esses espaços heterotópicos forjados pelas mulheres, mesmo que menores e com ações frágeis, podem fazer surgir o acontecimento transgressivo e criador. Nesses espaços de fragilidade concreta, as mulheres se movimentam nas margens e para as margens dos saberes e dos poderes estabelecidos, buscando construir outros lugares, perpassados por outros saberes e outras relações de poder. Essas práticas de resistência impulsionam a desconstrução ${ }^{6}$ dos saberes e dos poderes que controlam e normalizam; impulsionam a produção incessante de alternativas contra o mandato patriarcal (SEGATO, 2003).

\footnotetext{
5 Quando falamos em "ações menores" e "ações maiores", não estamos qualificando umas e desqualificando outras. Entendemos esses conceitos a partir do que dizem Deleuze e Guattari (2014) na obra Kafka: por uma literatura menor. Os autores criaram o conceito de literatura menor como dispositivo para analisar a obra de Franz Kafka, que é considerada revolucionária por subverter a língua alemã. Nesse sentido, uma literatura menor não é a de uma língua menor, mas sim o que uma minoria faz em uma língua maior. Equivale a dizer que "menor não qualifica mais certas literaturas, mas as condições revolucionárias de toda a literatura no seio daquela que se chama grande (ou estabelecida)" (DELEUZE; GUATTARI, 2014, p. 39).

${ }^{6}$ Entendemos o conceito de desconstrução conforme Derrida e Roudinesco (2004). Eles dizem que desconstruir uma narrativa "consiste em desfazer, sem nunca destruir, um sistema de pensamento hegemônico e dominante. Desconstruir é de certo modo resistir à tirania do Um, do logos, da metafísica (ocidental) na própria língua em que é enunciada, com a ajuda do próprio material deslocado, movido com fins de reconstruções cambiantes" (Derrida \& Roudinesco, 2004, p. 9).
} 
Muitas "artes de viver" e de "saber" na história das mulheres produziram um pensamento que, por seu caráter fugidio, intempestivo, mantêm uma relação direta com o movimento/acontecimento. É o caso das lutas feministas no Brasil - como as batalhas pelo voto e pelo livre acesso das mulheres ao campo de trabalho, encampadas pela Federação Brasileira pelo Progresso Feminino no ano de 1922; pela aprovação da lei do divórcio e pela criação do Movimento Feminino pela Anistia no ano de 1975, considerado o Ano Internacional da Mulher. É o caso também, nos anos 1980, do Movimento das Margaridas - mulheres trabalhadoras rurais - que através de intensa mobilização conquistaram o direito à cidadania, à aposentadoria rural e ao salário maternidade; das redes de diálogos intra e intermovimentos feministas que se constroem através de Organizações não Governamentais (ONGs); das redes de articulação, como a Articulação de Mulheres Brasileiras e a Marcha Mundial das Mulheres, dentre tantos outros acontecimentos.

Embora esses movimentos tenham como parâmetro o mundo cotidiano das mulheres - a família, a localidade e suas condições de vida -, que caracteriza a forma tradicional de identificação social da mulher, eles propiciaram uma visibilidade para as mulheres como sujeitos políticos. Ao questionarem, de diferentes maneiras, a condição da mulher e pôr em discussão a identidade de gênero, fazem circular um conjunto de enunciados que atravessam os discursos instituídos, que apontam os limites das verdades estabelecidas e, desse modo, possibilitam a criação de outros modos de vida - vidas não mais abafadas pelo poder que controla, normaliza e naturaliza.

Ao questionarem as biopolíticas do Estado - neste caso, no que se refere, entre outros, ao direito ao voto, aos direitos sexuais e reprodutivos, ao salário maternidade e ao direito à aposentadoria - essas mulheres questionam um conjunto de relações de poder empenhadas em produzir uma conformação dos corpos e dos sujeitos, empenhadas em produzir subjetividades que se adaptem à cultura patriarcal e criem possibilidades de vida para além das técnicas disciplinares e das biopolíticas. São movimentos/acontecimentos de mulheres que rompem com aquilo que historicamente foi estabelecido como "correto", como "moralmente aceito", como norma geral que 
rege a vida; são movimentos/acontecimentos que marcam certos espaços pela transgressão, pelo desvio ou, como diz Deleuze (2009), pelas heterotopias de desvio.

Ao questionarem o mandato patriarcal (SEGATO, 2003), as mulheres estão questionando o conjunto de relações de forças hegemônicas na sociedade e, com isso, fendem o sentido comum das coisas; fazem irromper uma multiplicidade de possibilidades, de forças singulares; fazem da sociedade patriarcal um espaço de instabilidade. Referindo-se a Foucault, Deleuze diz que toda forma de questionamento, de queixa - seja de normas, práticas, valores - "tem uma grande importância não só poética, mas histórica e social, porque exprime um movimento de subjetivação [...]. O sujeito nasce nas queixas tanto quanto na exaltação" (DELEUZE, 2013b, p. 193). A importância dessas ações, para Deleuze (2013b), está, não no resultado que as findaria, mas na qualidade de seus cursos e na potência de sua continuação.

Ao colocar em discussão os valores que norteiam a sociedade e que perpassam as práticas cotidianas - o habitus -, também questionando os reflexos disso na constituição dos sujeitos, as mulheres mostram seu descontentamento com uma prática cultural e histórica que cuidadosamente delimita, controla e regula seus corpos, seus comportamentos e suas condutas, através dos discursos religioso, político e médico. Seus questionamentos denunciam um conjunto de formas reguladas de viver, de sentir e de ser. A potência desses questionamentos consiste na possibilidade de desnaturalizar o que pensamos e visibilizar as diferentes subjetividades - insubmissas, transgressoras, rebeldes, críticas do seu próprio tempo.

As mulheres, através das práticas de resistência que colocam em movimento na história, criam, cada qual à sua maneira, modos singulares de existências. ${ }^{7}$ Ao escreverem/viverem sua história - sendo ousadas e recatadas, desbocadas e pudicas, sexuais e etéreas - passam a produzir um devir político ou, como diz Deleuze (2012) um pensamento "nômade", aberto às conexões, um pensamento que se desvia dos

\footnotetext{
${ }^{7} \mathrm{~A}$ história do Brasil está repleta de exemplos de mulheres que criaram modos singulares de existência: a escritora Maria Firmina dos Reis, a artista Tarsila do Amaral, Leila Diniz, Chiquinha Gonzaga, Patrícia Galvão, Nizia Floresta, dentre inúmeras outras. Mulheres que adentram um espaço proibido, por águas desconhecidas, e se aventuram, ousam, experimentam, se fazem perceber em um mundo que não as percebe; articulam a si próprias suas experiências de mulher. Constroem uma expressão própria que, através de uma fissura, uma fenda, uma linha de fuga, traçam um outro espaço, um outro existir.
} 
processos de subjetivação manipulantes e ditantes de regras e condutas do patriarcado. São gestos e movimentos que produzem novos modos de se conduzirem, de governarem a si mesmas, que criam estratégias e práticas de resistências como ato político. Ao pensarem, agirem e se posicionarem no mundo de outra maneira, as mulheres se inventam no imprevisível de fugas-intensivas.

Livres, essas mulheres procuram escapar das maquinarias que o poder aponta em cada passagem da história; desfazem as amarras engessantes que impedem o pensar e a ação de corpos diferentes. Elas produzem, no próprio desvio, uma maneira de seguir adiante sem serem capturadas; elas transformam esse desvio em uma aprendizagem potente para suas vidas; elas criam existências possíveis. São mulheres consideradas "infames", são corpos insubmissos que abalam, como afirma Segato (2012), as velhas práticas da colonialidade do gênero.

Os corpos que transgridem o espaço normativo, que transgridem a razão colonial, tornam-se problema para a sociedade patriarcal. Na rua, na esquina, na feira, nos jornais, na revolução, na passeata, esses corpos abalam, escandalizam; são, segundo Butler (2000), “corpos que pesam”; são corpos desviados, transgressores e racializados, que questionam estruturas profundamente enraizadas porque não aceitam uma vida que quer confinar.

Por isso, na história das mulheres - lugar de inscrição dos acontecimentos -, o corpo é "o lugar prático de controle social” (FOUCAULT, 1988, p. 15) e também o lugar/espaço de resistência, lugar de mando, de influência. O corpo da prostituta, da escrava, da louca, da histérica, da mendiga, da solteirona era, por um lado, o lugar de ataque por parte das investidas do poder, já que, portadoras do exótico, seu corpo revelava outra performance, a exuberância do prazer, do desvio mental, da outra cor, dos afloramentos do desejo, de gestos e sinais que fugiam ao controle normalizador; por outro lado, o corpo dessas mulheres também representava a possibilidade de mudança, a capacidade de desestruturar e abalar os ultrapassados códigos morais que sustentavam as relações de gênero. 
Ainda hoje o corpo das mulheres continua sendo na história, por um lado, o espaço que ocupa, suas fronteiras, as intervenções que nele se operam, a imagem e as narrativas que dele se produz, as "máquinas de guerra" 8 que nele tentam se conectar, os sentidos que nele marcam, os silêncios que por ele falam, os vestígios. Por outro lado, ao resistirem ao enquadramento do mandato patriarcal, o corpo das mulheres potencializa um conjunto de forças capazes de provocar mudanças extraordinárias nos modos de existência instituídos.

Diante disso, podemos dizer que, em muitos momentos, a história das mulheres foi construída pelo não factual, pelo não dito. Logo, o conhecimento histórico feminino se situa em um território aquém do instituído. É no interior desse território - desse "espaço outro" - que as práticas femininas, enquanto acontecimento, permanentemente atualizam forças, lutas, embates e contradições entre diferentes interesses e significados. O acontecimento, diz Deleuze e Parnet é sempre produzido “por corpos que se entrechocam, se cortam ou se penetram, a carne e a espada, mas tal efeito não é da ordem dos corpos, batalha impassível, incorporal, impenetrável, que domina sua própria realização e domina sua efetuação" (DELEUZE; PARNET, 1998, p. 78). Então, as práticas femininas são acontecimento porque há nelas "uma parte que sua realização não basta para realizar, um devir em si mesmo que está sempre, a um só tempo, nos esperando e nos precedendo como uma terceira pessoa do infinitivo, uma quarta pessoa do singular" (DELEUZE; PARNET, 1998, p. 78). Ou seja, as práticas femininas, enquanto acontecimento, são movimento, devir; e trazem consigo a possibilidade de mudança nos sistemas de pensamento hegemônicos.

Então, podemos dizer que na história das mulheres, as resistências foram fundamentais para a criação de espaços outros para viver, pensar; espaços ainda não capturados pelos dispositivos de saber-poder. As resistências das mulheres, neste caso, são um gesto político, uma potência política que, do interior das relações de poder, nasce como potência de criação da vida - um desafio aos sistemas instituídos. Afirmamos isso

\footnotetext{
${ }^{8}$ Deleuze (2013) define a máquina de guerra "como um agenciamento linear construído sobre linhas de fuga. Nesse sentido, a máquina de guerra não tem, de forma alguma, a guerra como objeto, tem como objeto um espaço muito especial, espaço liso, que ela compõe, ocupa e propaga. O nomadismo é precisamente essa combinação máquina de guerra-espaço liso" (DELEUZE, 2013, p. 47).
} 
porque pensamos com Foucault (2008) que a "política não é nada mais, nada menos do que o que nasce com a resistência a governamentalidade, a primeira sublevação, o primeiro enfrentamento" (FOUCAULT, 2008, p. 287). E a potência política das práticas de resistência que as mulheres desenvolvem tem a força de desestabilizar as linhas estabelecidas, de deslocar as relações, liberando a vida para que se organize cada vez mais em novas formas e com novas práticas.

\section{4- Algumas considerações}

Os espaços de "vida outra" forjados pelas mulheres são, na história das mulheres, um ato criativo de resistência. Através das fissuras, das linhas de fuga, as mulheres se conectaram a devires que levaram a acontecimentos históricos e a novas formas de vida. Compreender esses espaços em seu potencial libertário não apenas permite a autonomia, mas reafirma práticas que sempre foram, na história das mulheres, o reflexo de uma arte revolucionária e inventiva; e, dentro de suas possibilidades, um importante marco de resistência.

Isso nos leva a entender a história das mulheres a partir daquilo que Deleuze e Guattari (2012) denominam de pensamento nômade - um pensamento aberto, indefinido, não comunicante. Ou seja, nos leva a compreender a história das mulheres como uma história que trata do passado com toda sua capacidade inventiva, um pensamento historiográfico indomado, um pensar e agir feminino levado a sério, que perambula em "espaços outros", da des-razão, do não oficial, do instável, do não visível, do condenável, do proibido, do não aceitável, das resistências e de outros modos de existência.

Por isso, as práticas de resistência na história das mulheres não são simples oposições às relações de poder hegemônicas; são ações que afirmam a vida, esta vida de mulheres - que se perde constantemente frente às tentativas de reprodução do mesmo. Afirmamos isso porque pensamos, com Foucault, que a capacidade que a vida tem de resistir às relações de poder que pretendem geri-la é inseparável das possibilidades de composição de forças singulares e das transformações que ela pode alcançar. Resistir, nesse sentido, significa criar. E, se não há exterioridade ao poder, como 
nos ensinou Foucault, o que as mulheres fizeram/fazem é produzir linhas de fuga no próprio espaço controlado e normalizado da história. É como criar saídas, re-existir, existir novamente, vazar, transbordar os constrangimentos postos por um discurso com pretensões de universalidade, linearidade, identidade e liberar a vida. Para quê? Para transbordar em uma multiplicidade de imprevisíveis possibilidades.

\section{Referências}

BUTLER, Judith. Corpos que pesam. In: LOURO, Guacira Lopes. (Org.). O corpo educado. Belo Horizonte: Autêntica, 2000, p.153-171.

CERTAU, Michel de. A invenção do Cotidiano: artes de fazer. Ed. Vozes. Petrópolis.1996.

DELEUZE, Gilles e GUATTARI, Félix. Kafka: por uma literatura menor. Belo Horizonte: Autêntica Editora, 2014.

DELEUZE, Gilles. Deleuze e Guattari explicam-se. In: DELEUZE, Gilles. A ilha deserta. São Paulo: Iluminuras, 2006. p. 277-292.

DELEUZE, Gilles. Foucault. São Paulo: Brasiliense, 2013a.

DELEUZE, Gilles. Um retrato de Foucault. In: DELEUZE, Gilles. Conversações. 3. ed. São Paulo: Editora 34, 2013b. p. 131-151.

DELEUZE, Gilles. Mil Platôs: capitalismo e esquizofrenia. São Paulo: Editora 34, 2012.

DELEUZE, Gilles; PARNET, Claire. Diálogos. São Paulo: Editora Escuta,1998.

DERRIDA, Jacques e ROUDINESCO, Elisabeth. De que amanhã... diálogos. Rio de Janeiro: Jorge Zahar Editor, 2004.

DUARTE, André. Biopolítica e resistência: o legado de Michel Foucault. In: RAGO; Margareth, VEIGA-NETO, Alfredo. (Orgs.). Figuras de Foucault. 2. ed. Belo Horizonte: Autêntica, 2008, p. 45-55. 
FOUCAULT, Michel. A coragem da verdade. São Paulo: Editora WMF Martins Fontes, 2011.

FOUCAULT, Michel. A vida dos homens infames. In: FOUCAULT, Michel. Ditos e Escritos IV: estratégias saber-poder. 3. ed. Rio de Janeiro: Forense Universitária, 2015. p. 199-217.

FOUCAULT, Michel. História da sexualidade: a vontade de saber. 13. ed. Rio de Janeiro: Edições Graal, 1988.

FOUCAULT, Michel. O sujeito e o poder. In: DREYFUS, Hubert L. ; RABINOW, Paul. Michel Foucault: uma trajetória filosófica: para além do estruturalismo e da hermenêutica. 2. ed. Rio de Janeiro: Forense Universitária, 2013. p. 273-295.

FOUCAULT, Michel. Outros espaços. In: FOUCAULT, Michel. Ditos e Escritos III: estética: literatura e pintura, música e cinema. 2. ed. Rio de Janeiro: Forense Universitária, 2009. p. 411-422.

FOUCAULT, Michel. Ditos e escritos IV: estratégias saber-poder. 3. ed. Rio de Janeiro: Forense Universitária, 2015. p. 172-185.

FOUCAULT, Michel. Segurança, território, população: Curso ministrado no Collège de France (1977-1978). São Paulo: Martins Fontes, 2008.

FOUCAULT, Michel. Sobre a Genealogia da ética. In: FOUCAULT, Michel. Ditos e escritos IX: genealogia da ética, subjetividade e sexualidade. Rio de Janeiro: Forense Universitária, 2014. p. 214-237.

GALLO, Silvio. Cuidar de si e cuidar do outro: implicações éticas para a educação dos últimos escritos de Foucault. In: GONDRA, José; KOHAN, Walter. (Orgs.). Foucault 80 anos. Belo Horizonte: Autêntica, 2006. p. 177-189.

GALLO, Silvio. Pensar a escola com Foucault: além da sombra da vigilância. In: CARVALHO, Alexandre Filorde de; GALLO, Silvio. (Orgs.). Repensar a educação: 40 anos após Vigiar e Punir. São Paulo: Editora Livraria da Física, 2015. p. 427-449.

GROS, Frédéric. Situação do curso. In: FOUCAULT, Michel. A coragem da verdade: 0 governo de si e dos outros II. São Paulo: Editora WMF Martins Fontes, 2011. p. 301-316.

GROS, Frédéric. Situação do curso. In: FOUCAULT, Michel. A hermenêutica do sujeito. São Paulo: Martins Fontes, 2006. p.613-661.

PELLEJERO, Eduardo. Dos dispositivos de poder ao agenciamento da resistência.

Disponível em: http://www.comciencia.br/comciencia/?section=8\&edicao= 35\&id=419\&tipo=1. Acesso em: 28 de dezembro de 2017. 
PERROT, Michelle. As mulheres ou os silêncios da história. São Paulo; EDUSC, 2005.

RAGO, Margareth. O feminismo acolhe Foucault, labrys, 2014. Disponível em: https://www.labrys.net.br/labrys26/foucault/margaok.htm. Acesso em: 02 de março de 2018.

REVEL, Judith. Michel Foucault: conceitos essenciais. São Carlos: Claraluz, 2005.

SEGATO, Rita Laura. Gênero e colonialidade: em busca de chaves de leitura e de um vocabulário estratégico descolonial. E-cadernos ces, n.18, 2012. p. 106-131.

SEGATO, Rita Laura. Las estructuras elementales de la violência: ensayos sobre género entre la antropología, el psicoanálisis y los derechos humanos. Bernal, Argentina: Universidad Nacional de Quilmes, 2003.

THÉBAUD, Françoise. Escribir la história de las mujeres y del género. Ediciones KRK. Oviedo: Espãna, 2013.

VILELA, Eugênia. Resistência e acontecimento: as palavras sem centro. In: GONDRA, José; KOHAN, Walter. (Org.). Foucault 80 anos. Belo Horizonte: Autêntica, 2006. p. 107-127. 